\title{
Research on Properties of Polymethyl Methacrylate Colored Non-slip Surface Coating
}

\author{
Yongqiang Zhong ${ }^{1, a}$ \\ ${ }^{1}$ Transportation College, Huaiyin Institute of Technology, Huai'an 223003, China \\ a email: zyqjlu@126.com
}

Keywords: Polymethyl methacrylate; Colored Non-slip Surface Coating; Properties experiment

\begin{abstract}
Colored non-slip surface coating has an important role in the prevention of traffic accidents and obtains more and more attention and application. This paper based on chemical reaction principle of poly methyl methacrylate with a curing agent to produce a fast secondary crosslinking reaction coating mix. On the basis of the principle, test measures are designed to test performance of curing time and Bond strength. It is the basis for the application of the material.
\end{abstract}

\section{Introduction}

Europe, America and Japan and other developed countries have already carried out research and development in colored non-slip surface coating. Color non-slip pavement has been used in parking lot, bus lanes, bicycle lanes, accident-prone points. Plane structure is shown in figure 1.Currently the application of colored non-slip surface of our country is not a lot. Our research for skid technology began in the 1970s and colored asphalt mixture Discussion began in 1980s[1][2]. Due to the constraints of various technical conditions, colored non-slip surface technology of our country than in other countries is also behind a lot.

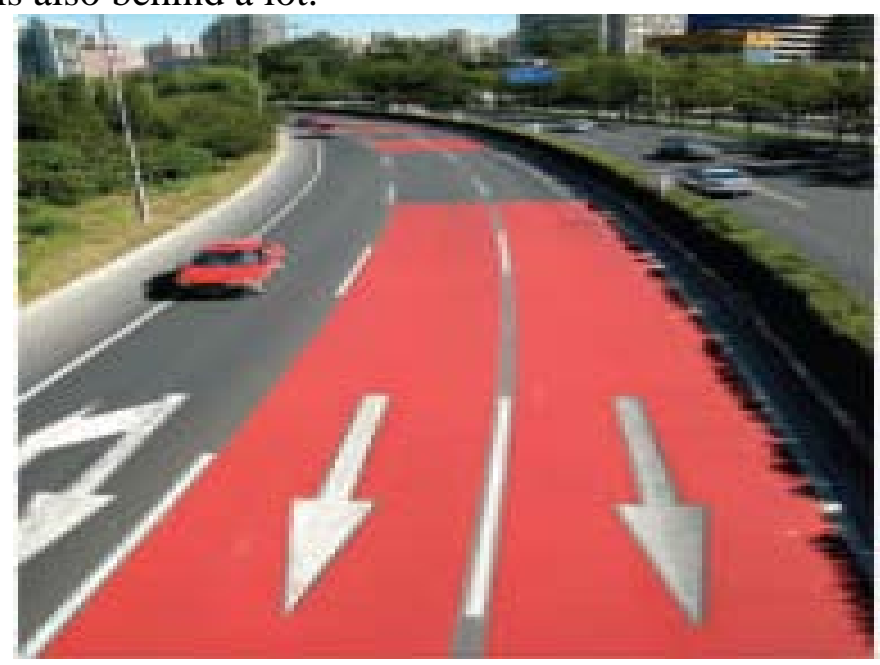

Fig. 1 Plane structure

\section{Chemical reaction mechanism of two-component material coating of polymethyl methacrylate}

Polymethyl methacrylate polymer binder is a two-component material. The curing agent is added in the construction of another resin component .The curing agent makes methacrylic acid MMA monomer (molecular weight 100) to produce fast secondary crosslinking reaction and ultimately the formation of high-strength film[3]. Methyl methacrylate endows polymer greater cohesive strength. So it belongs to a hard monomer which is shown in Figure 2[4]. Performance of methacrylic resin depends on the selected size of the resin monomer structure and molecular weight [5]. The $a$ position of methyl methacrylate is substituted by the vinyl, eliminating the breaking point of oxidized to ensure the good weatherproof and durability[6]. The curing time can be artificially controlled which is shown in Figure 3. 

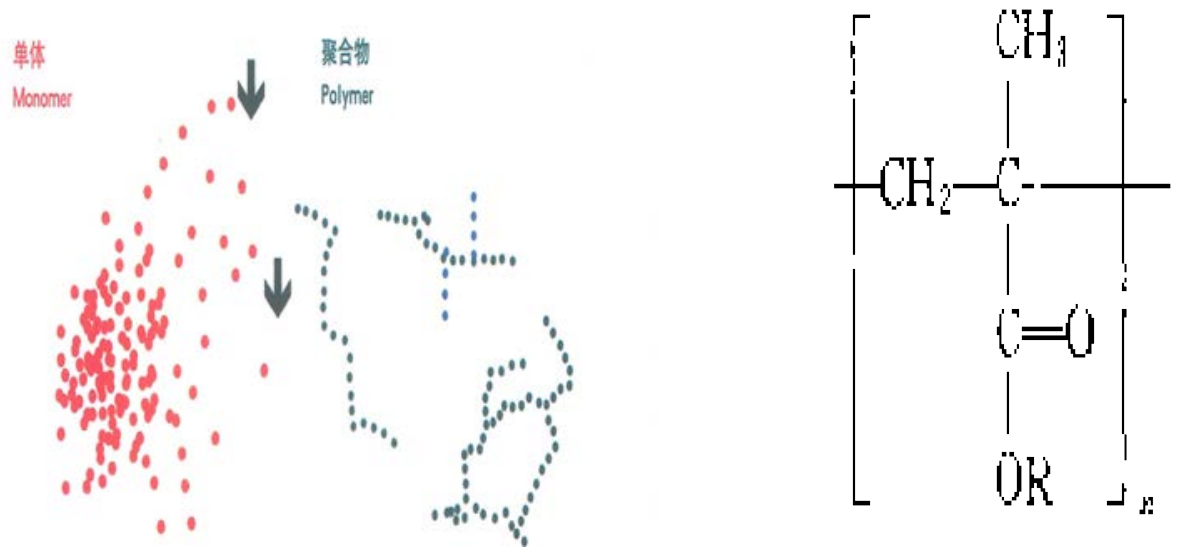

Fig. 2 The monomers and polymers schematic diagram and polymer chemistry formula

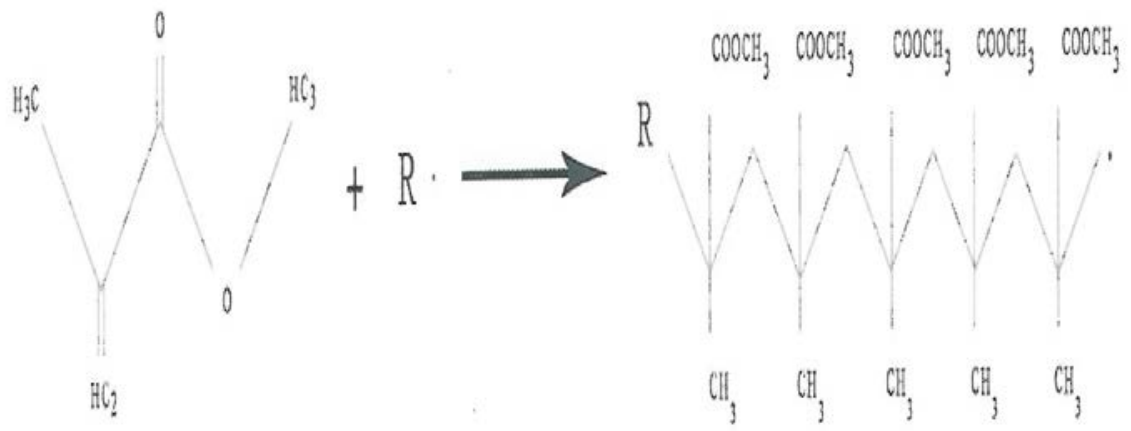

Fig.3 Two-component resin polymerization reaction schematic diagram

Based on the above physical and chemical properties, the main advantages of polymethyl methacrylate resin color slip coating are below[7][8]:

(1) the opening to traffic fast, small impact on traffic and excellent slip resistance;

(2) no ramaway, no security risks and green environmental protection;

(3) applies to a variety of substrates such as cement, asphalt, metal, wood, ceramics, stone.

\section{Material composition design and the solidification time test}

Performance testing is done to polymethyl methacrylate adhesive of adding the curing agent of $1 \%, 2 \%, 3 \%, 4 \%, 5 \%$ different proportions. The specific design of the material composition is shown in Table 1.

Tab.1 Material composition design table of two component polymethyl methacrylate

\begin{tabular}{ccc}
\hline The number of groups & the main agent/g & curing agent/g \\
\hline 1 & 100 & 1 \\
2 & 100 & 2 \\
3 & 100 & 3 \\
4 & 100 & 4 \\
5 & 100 & 5 \\
\hline
\end{tabular}

The solidification time results of different composition of polymethyl methacrylate materials are shown in Table 2. The curing time of the binder distributes within $1 \mathrm{~h}$. With the increase of the curing agent content, curing time reduces. When the curing agent content is $5 \%$, solidification time is the fastest. 
Tab.2 Solidification time results of different composition of polymethyl methacrylate materials

\begin{tabular}{ccc}
\hline Curing agent content/\% & Time period & Solidification time $/ \mathrm{h}$ \\
\hline 1 & $8: 51 \sim 9: 44$ & 0.88 \\
2 & $8: 58 \sim 9: 46$ & 0.80 \\
3 & $9: 03 \sim 9: 50$ & 0.78 \\
4 & $9: 20 \sim 10: 05$ & 0.75 \\
5 & $9: 14 \sim 9: 56$ & 0.70 \\
\hline
\end{tabular}

\section{The bond strength test}

\section{Test Method}

The experiment was bond strength test after two-component of the main agent and curing agent solidification which is shown in Figure 4 . Two cement test blocks of $4 \mathrm{~cm}$ wide and $1 \mathrm{~cm}$ in thickness was used. Laboratory equipment and materials were tensile testing machine, tensile special fixtures, temperature and humidity conservation tank, cement block making molds, cement, gravel, curing agents, Polymethyl methacrylate, scraper and so on.

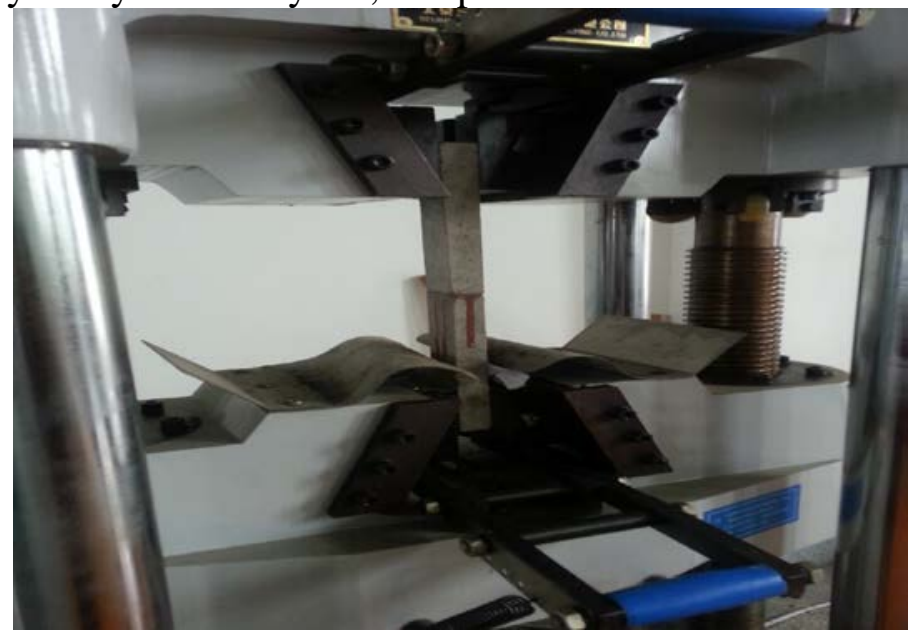

Fig. 4 Tensile test site graph

\section{Material strength test results of polymethyl methacrylate}

Different tensile results of polymethyl methacrylate materials are shown in Table 3.

Tab. 3 Tensile test results of polymethyl methacrylate

\begin{tabular}{lccccc}
\hline Curing agent content $/ \%$ & 1 & 2 & 3 & 4 & 5 \\
\hline Force value $/ \mathrm{KN}$ & 5.40 & 5.38 & 5.30 & 5.22 & 5.12 \\
Displacement/mm & 1.20 & 1.29 & 1.36 & 1.33 & 1.28 \\
\hline
\end{tabular}

According to formula (1) ,polymethyl methacrylate adhesive strength can be calculated in table 4. The value of bond strength ranges from 32Mpa to 35Mpa. From the experimental data, it can be seen that the best mechanical properties can be obtained when the main agent with a curing agent mass ratio of 100: 1 .

$$
\begin{aligned}
& \text { C }=1.8 \mathrm{QT} / 0.7 \\
& \text { QT- tensile strength }(\mathrm{KN}) \\
& \text { C- bond strength (Mpa) }
\end{aligned}
$$


Tab.4 Polymethyl methacrylate bond strength results

\begin{tabular}{lccccc}
\hline $\begin{array}{l}\text { Curing } \\
\text { content /\% }\end{array}$ & agent & 1 & 2 & 3 & 4 \\
\hline Bond strength /Mpa & 34.71 & 34.59 & 34.07 & 33.58 & 32.92 \\
\hline
\end{tabular}

\section{Conclusions}

When the binder is added $1 \%, 2 \%, 3 \%, 4 \%, 5 \%$ curing agent, the curing time of the binder distributed within 1h.It belongs to quick-drying adhesive. With the increase of the curing agent content, curing time reduced. When the curing agent content is $5 \%$, the curing time is the fastest. It is conducive to rapid opening to traffic, saving time and less impact on traffic order. The value of bond strength ranges from 32Mpa to 35Mpa. From the experimental data, it can be seen that the best mechanical properties can be obtained when the main agent with a curing agent mass ratio of 100: 1 .

\section{Acknowledgement}

In this paper, the research was sponsored by the Project supported by the Natural Science Foundation of the Jiangsu Higher Education Institutions of China(Grant No. 15KJB580002) and Huaian science and technology development project (Project No. HAGZ2014007).

\section{References}

[1] Zhao Da-sheng, Sun Xiu-ying. Status quo and development trend of China's environmental protection adhesive [J] chemistry and bonding, 2009,31 (2): 51-53

[2] Davang S H, et al. Skid resistant coatings for aircraft carrier decks [J]. Coat Technol, 1980,52 (671): 65-69.

[3] Ma Zhong-nan .Research quality skid coatings and application technology [J] .Highway and Transportation Research: Application and Technology, 2012 ,(2): 89-92

[4] Luo Hai-bing. Colored pavement technical solutions and color non-slip surface design [J]. China Municipal Engineering, 2007, (2): 11-16.

[5] JT / T 712-2008, skid paint [S].

[6] Wang Jian-wen color non-slip material Application of New Technology in Highway [J]. Communications Standardization, 2011, (3): 184-186.

[7] Tao color pavement materials and construction technology research [D] .Xi'an: Chang'an University, 2006.

[8] Shao Qi, Li Aiguo, Ran Meng- Jiang. International Airport Highway colored pavement design and application [J] .Highway, 2009, (6): 193-196. 